\title{
Quality improvement to reduce chronic lung disease rates in very- low birth weight infants: high compliance with a respiratory care bundle in a small NICU
}

\author{
Zuzanna Kubicka $^{1,2} \cdot$ Eyad Zahr $^{1,2} \cdot$ Tamara Rousseau $^{1,2} \cdot$ Henry A. Feldman ${ }^{3} \cdot$ John Fiascone $^{1,2}$
}

Received: 6 June 2017 / Accepted: 11 October 2017 / Published online: 12 December 2017

(C) Nature America, Inc., part of Springer Nature 2018

\begin{abstract}
Objective Reduce chronic lung disease by $10 \%$ among very-low birth weight infants by implementing a consistent respiratory care bundle.

Study design Prospective quality improvement study of infants below 32 weeks gestation in a small neonatal intensive care unit. A respiratory care bundle to eliminate inter-provider variability and minimize use of mechanical ventilation was implemented. This included: defining delivery room management with use of continuous positive airway pressure/nasal intermittent positive pressure ventilation, uniform intubation/extubation criteria, and standardizing ventilation/post-extubation support.

Results A total of 107 very-low birth weight infants were included in this project. Compliance with the respiratory care bundle was $>90 \%$. Chronic lung disease rates at 36 weeks postmenstrual age fell from 43 to $12 \%(P=0.0006)$, rates of combined chronic lung disease/death decreased from 50 to $20 \%(P=0.002, \mathrm{OR}=0.25,95 \% \mathrm{CI} 0.1-0.6)$, rates of severe intraventricular hemorrhage decreased from 13 to $0 \%(P=0.005)$, and surgical ligation of patent ductus arteriosus decreased from 35 to $3 \%(P<0.0001)$.

Conclusion High compliance with the respiratory care bundle was achieved and a 73\% reduction in chronic lung disease rates in very-low birth weight infants occurred.
\end{abstract}

\section{Introduction}

Respiratory support of preterm infants at birth and during first weeks of life varies between institutions and practitioners [1]. Despite the combination of antenatal steroid exposure and surfactant therapy chronic lung disease (CLD) rates remain unacceptably high [2-6]. Several recent randomized, controlled trials tested continuous positive airway pressure (CPAP) against early intubation, mechanical

Electronic supplementary material The online version of this article (https://doi.org/10.1038/s41372-017-0008-4) contains supplementary material, which is available to authorized users.

Zuzanna Kubicka

zkubicka@southshorehealth.org

Boston Children's Hospital, Boston, MA, USA

2 South Shore Hospital, Weymouth, MA, USA

3 Clinical Research Center, Boston Children's Hospital, Boston, MA, USA ventilation, and surfactant. These studies and subsequent meta-analyses demonstrated a decrease in the incidence of CLD or death in infants stabilized on CPAP [7-12].

Review of our rate of CLD among very-low birth weight (VLBW) infants, defined as the need for oxygen or positive pressure support at 36 weeks, was higher than other neonatal intensive care units (NICUs) in the Vermont-Oxford Network (VON). Our VLBW CLD rate from 2011 to 2013 was $42.3-44.7 \%$ vs. $23.4-24.9 \%$ in the overall network. The standardized morbidity ratio (SMR) for CLD in our institution was 1.2-1.5. Additionally, our rates of CLD were consistently higher than the average rate of $23.2-26.7 \%$ among the seven Massachusetts NICUs in our statewide NICU quality collaborative (SMR 0.9-2.1).

The goals for our quality improvement (QI) project were to use a multidisciplinary process to develop and implement a bundle of evidence-based respiratory care practices that would reduce practice variation and lower the VLBW CLD rate by $10 \%$ within 2 years of implementation. This bundle is described in the "Respiratory Distress Syndrome (RDS) Management Guideline for Infants $<32$ weeks". We report 
here data from the 24-month period from 1 March 2014 to 29 February 2016 ("Implementation" phase).

\section{Methods}

\section{Context}

South Shore Hospital in Massachusetts has $~ 3600$ deliveries and 450 NICU admissions per year. The NICU has 30 beds, admits between 30 and 50 VLBW infant's per year, and is the only level 3 NICU in the state not located in an academic medical center. Infants are cared for by a staff of 7 neonatologists, 2 neonatal nurse practitioners, 8 pediatric/neonatal certified respiratory therapists, and 70 nurses. No physicians or neonatal nurse practitioners (NNPs) in training participated in patient care.

\section{Delivery room team composition, equipment, and respiratory care}

A Neopuff T-piece resuscitator (Fisher \& Paykel Healthcare) with blended oxygen was used in the delivery room (DR) for all high-risk deliveries after January 2012. Prior to this time flow-inflating resuscitation bags with adjustable FIO2 were used. Neonatal Resuscitation Program guidelines were followed during resuscitation. If positive pressure ventilation was needed, a NeoPuff and either an appropriate size mask or a RAM cannula (Neotech) were used. High-risk deliveries were always attended by a pediatric/ neonatal respiratory therapist, a nurse, and an NNP or neonatologist.

The only interface for CPAP and nasal intermittent positive pressure ventilation (NIPPV) delivery in the DR and during the NICU stay was the RAM cannula (Neotech) with size based on birth weight. In the NICU, both CPAP and NIPPV were delivered by either a Babylog VN500 or an Evita Infinity V500 ventilator (Draeger Medical). Saturation target parameters for infants $<32$ weeks gestational age (GA) were 88-92\% during the baseline year 2013 and implementation phase.

Included infants were inborn and $<1500 \mathrm{~g}$. All eligible infants are included in this report. Exclusion criteria were: GA below 24 weeks, congenital diaphragmatic hernia, congenital heart disease, choanal atresia, and a decision to forgo intensive care.

\section{Interventions}

We structured our QI initiative based on the Institute for Healthcare Improvement model with initial implementation of the guideline followed by multiple modifications to the interventions based on staff input and monitoring of data. A formal key driver diagram was not utilized.

The multidisciplinary guideline development and staff education took place from 1 January 2014 to 28 February 2014. The implementation phase included the period from 1 March 2014 to 29 February 2016.

\section{Guideline development}

A multidisciplinary task force was assembled that included representatives from the neonatologists, respiratory therapists, and nursing staff. The team leader coordinated the efforts and oversaw all the steps in bundle creation and introduction. All the staff including nurses, neonatologists, NNPs, respiratory therapists, medical director, nurse manager, clinical nurse educator, and respiratory therapy director were aware of the initiative, and were encouraged to provide the task force with input, which was incorporated into the Guideline.

The task force reviewed our respiratory practices during the year 2012 (full VON outcome data for the year 2013 were not completed yet) when practices were nonstandardized and dependent entirely on the physician's choice. A "snapshot" of our respiratory management was created by detailed review of all 11 VLBW infants diagnosed with CLD in 2012. All 11 infants were intubated in the DR and received surfactant. High-frequency oscillatory ventilation (HFOV) and sedation were initiated on admission for all infants, early extubation was attempted in only one case. Ultimately, all infants underwent prolonged mechanical ventilation and high-flow nasal cannula (HFNC) therapy.

The task force reviewed relevant literature and developed a framework for respiratory management for all infants 24-32 weeks GA [1, 6-18]. The task force visited a NICU with a very-low incidence of CLD that focused on bubble CPAP and reviewed their intubation/extubation criteria and discussed how they had achieved high compliance.

Major changes in our practice included an emphasis on non-invasive ventilation: defining DR management with the use of CPAP/NIPPV as the primary mode of respiratory support, encouraging uniform intubation/extubation criteria, use of HFOV as a "rescue mode" only, and avoidance of over sedation and standardized post-extubation support (for Guideline summary see Supplementary information available at JPER website).

Members of the multidisciplinary task force provided intense training to the NICU staff members. Training was discipline specific and consisted of small group Power Point sessions led by a neonatologist and a multidisciplinary team member from the same discipline (specialists training specialists approach). During these sessions, data from our NICU were compared to the network CLD rates and the 
rationale for a non-invasive ventilation approach was presented. The Guideline was discussed and clarified when necessary, and the technique of how CPAP and NIPPV were to be provided was reviewed. Copies of the algorithm with detailed steps of respiratory care along with pocket sized, laminated cards with an abbreviated version of the Guideline were placed in the NICU as close as possible to the point of care.

\section{Guideline implementation}

The Guideline was implemented on 1 March 2014. The team leader coordinated the efforts, oversaw all the steps and communicated compliance outcomes in a collegial way with the team during monthly meetings. Feedback from clinical staff, including physicians, nurses, and respiratory therapists, was solicited continuously and several modifications to the Guideline were made as a result of staff feedback. These included: attention to frequent stomach decompression due to gas trapping during NIPPV and CPAP, clearing nasal/oral secretions, and avoiding disconnection of CPAP apparatus during "hands-on" nursing care including turning and weighing.

Refresher activities took place after completion of 12 and 24 months of the implementation phase. These included an online quiz about the Guideline, and a formal presentation for all staff summarizing the 12- and 24-month outcomes and compliance. Our success was shared and celebrated with the entire staff after completing 12 and 24 months. We also presented our methods and outcomes at regional QI meetings and with other NICUs at local meetings.

Minor Guideline changes were implemented after completion of the first 12 months. Discontinuation of CPAP therapy for infants $<28$ weeks at birth when stable in room air (RA) without the need for any respiratory support and inclusion of infants 23-24 weeks in the Guideline were allowed. These modifications were based on increasing experience with extremely preterm infants and were communicated in the refresher activities.

\section{Study of the interventions}

All the data on compliance, maternal and neonatal characteristics, and respiratory management and outcomes during the 24 months of the implementation phase were collected prospectively by three neonatologists, who were task force members. The "Baseline" year 2013 data were obtained by retrospective chart review. The timing of our implementation phase (1 March 2014-29 Feb 2016) did not match yearly reported VON data; therefore none of the data were extrapolated from VON reporting.

\section{Process measures and outcomes}

To monitor compliance with the Guideline, a "Compliance Data Sheet" was maintained for each VLBW infant by three neonatologists, who were task force members. DR interventions, intubation, number of days on synchronized intermittent mandatory ventilation (SIMV), HFOV, NIPPV, CPAP, HFNC, low-flow nasal cannula (LFNC), surfactant administration, and caffeine therapy were monitored and used as measures of compliance.

The primary outcomes were the rate of CLD and combined CLD/death. CLD was defined as supplemental oxygen or positive pressure use at 36 weeks postmenstrual age and included infants transferred before 36 weeks and readmitted. If the infant was transferred before 36 weeks on supplemental oxygen or positive pressure, not readmitted and the 36 week data were not available, the diagnosis of CLD was made. If the infant was discharged home with oxygen between 34 and 36 weeks, CLD was diagnosed. Additionally, infants requiring at least 28 days of supplemental oxygen and supplemental oxygen with effective FIO2 $<0.3$ at 36 weeks postmenstrual age were classified as moderate CLD and those requiring FIO2 $\geq 0.3$ as severe CLD $[19,20]$.

Secondary outcomes included: need for supplemental oxygen at home, need for medical/surgical therapy for echocardiography proven patent ductus arteriosus (PDA), need for vasopressive agents to treat hypotension, need for postnatal steroids for CLD, and length of stay.

Balancing measures were collected separately from the routine VON data. Severe intraventricular hemorrhage (IVH) diagnosed by intracranial imaging on or before day 28 of life. Grade 3 IVH was defined as intraventricular blood and ventricular dilatation; grade 4 as intraparenchymal bleeding [21]. Severe retinopathy of prematurity (ROP) was defined as stage 3-4 or requiring surgery as described by International Committee for the Classification of ROP standards [22]. Necrotizing enterocolitis (NEC) was diagnosed as Modified Bell criteria stage 2 or higher [23]. Nosocomial infection, pneumothorax, and spontaneous intestinal perforation definitions approximated the VON definitions.

\section{Analysis}

Performance on the primary outcome measure and respiratory care practices were monitored using statistical process control charts, and rules for detecting special cause variation were applied [24]. There were a different number of VLBW infants born each month and quarterly with unequal opportunity for an event, therefore U-charts were created with means, upper, and lower control limits (three standard deviations above and below the mean, respectively) calculated using QI Macros SPC 2017 software. In addition, demographic and clinical characteristics between the baseline year and implementation phase 
were compared using Fisher's exact test (2-sided) to assess associations between categorical variables. Simple logistic regression was used to compare binary outcomes between study phases. Student's independent-sample $t$ test (2-sided) was used to assess differences in means for continuous measures. For skewed measures, the Wilcoxon rank-sum test was used to compare distributions. SAS software (Cary, NC) was used for all statistical computations.

We analyzed data on infants $<1500 \mathrm{~g}$ rather than $<32$ weeks GA to maintain consistency with VON data and to compare our outcomes with our local QI network.

\section{Ethical considerations}

The Guideline was introduced as a prospective QI project and was exempted from approval by the South Shore Hospital Institutional Review Board.

\section{Results}

One hundred-ten infants with a birth weight of $<1500 \mathrm{~g}$ were born at South Shore Hospital between January 2013 and March 2016. Three infants were excluded from analysis: one infant with trisomy 18 forgoing intensive care, one with GA 22 weeks, and one with pulmonary hypoplasia and death within $2 \mathrm{~h}$. Out of the 107 infants analyzed, 46 were born during baseline year 2013 and 61 during the implementation phase.

As shown in Fig. 1, during the implementation phase the rate of CLD fell over time from 37 to $10 \%$. Criteria for special cause variation were met with eight consecutive points below the mean [24]. Also shown in Fig. 1 are implementation phase changes in DR intubation (53-11\%) and HFOV exposure (57-19\%). These process measures also meet criteria for special cause variation. Of note, the CLD rates for our Massachusetts QI collaborative remained $25.3 \%$ and $23.9 \%$ in 2014 and 2015, respectively.
There were deviations from the Guideline involving three patients $(3 / 61=4.9 \%$ infants). One infant $<28$ weeks GA was extubated to RA rather than NIPPV or CPAP, one infant $<28$ weeks GA was weaned to HFNC prior to 32 weeks GA, and one infant $<28$ weeks GA was weaned from CPAP when criteria were not met. The goal of extubation within $2 \mathrm{~h}$ of meeting the criteria was not strictly followed, but was always $<6 \mathrm{~h}$.

Table 1 provides the summary of maternal and neonatal characteristics. There were no statistically significant differences between groups in any of the attributes examined except, with marginal statistical significance $(P=$ 0.05-0.07), that infants in the implementation phase were on an average $106 \mathrm{~g}$ heavier, 1 week older, more likely to be male, and the birth weight of $<1000 \mathrm{~g}$ was less prevalent.

Significant differences in respiratory management between the baseline year 2013 and implementation phase were noted (Table 2). In the DR, infants were significantly more likely to be managed with NIPPV and significantly less likely to be intubated. After admission to the NICU: intubation, mechanical ventilation with SIMV or HFOV, surfactant administration, HFNC therapy, LFNC therapy, and number of days spent on HFNC/LFNC, were all significantly lower. Caffeine therapy was started on admission significantly more often. Postnatal steroid administration was less common during the implementation phase, this almost reached statistical significance $(P=0.054)$. We did not find a significant difference in overall frequency of CPAP or NIPPV use or median number of days spent on those modalities.

There was a significant reduction in the incidence of CLD among all VLBW infants (from 43 to $12 \%, P=$ 0.0006) and the combined outcome of CLD/death (from 50 to $20 \% P=0.002, \mathrm{OR}=0.25,95 \%$ confidence interval $(\mathrm{CI})$ 0.1-0.6). All the infants diagnosed with CLD were $<32$ weeks GA at birth. Among infants with CLD, the proportion of severe CLD decreased, but the sample size was too small to demonstrate statistical significance $(P=$ 0.36 by Fisher exact test). We did not find a significant
A

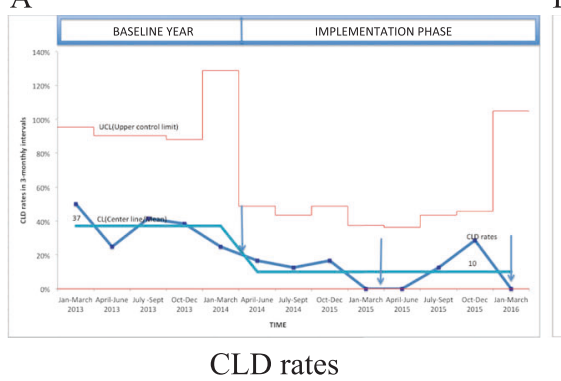

B

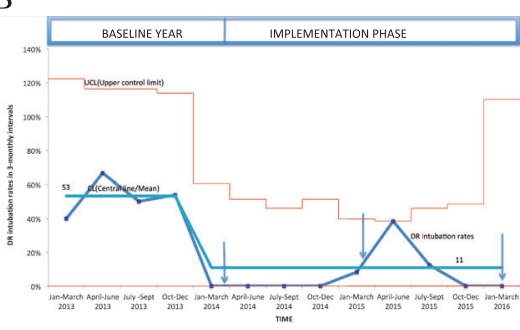

DR intubation rates

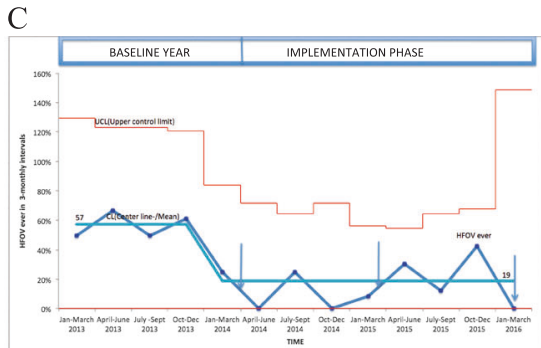

HFOV use at anytime
Fig. 1 Control chart (U-chart) of CLD rates, DR intubation rates, and HFOV use at anytime in quarterly intervals during 1 January 2013-29 February 2016. Arrows represent the end of baseline year, the end of
12 months of the implementation phase, and the end of 24 months of the implementation phase, respectively 
Table 1 Maternal and neonatal characteristics

\begin{tabular}{llll}
\hline Characteristic & $\begin{array}{l}\text { Mean } \pm \text { SD }, N(\%), \text { or median } \\
(25 \text { th-75th percentile })\end{array}$ & \multirow{2}{l}{$P$-value* } \\
\cline { 2 - 3 } & $\begin{array}{l}\text { Baseline } \\
\text { year }\end{array}$ & $\begin{array}{l}\text { Implementation } \\
\text { phase }\end{array}$ & \\
\hline All infants & $46(100)$ & $61(100)$ & - \\
Gestational age at & $28.4 \pm 2.8$ & $29.4 \pm 2.9$ & 0.06 \\
birth, weeks & & & \\
Birth weight, g & $1026 \pm$ & $1132 \pm 275$ & 0.06 \\
Birth weight <1000g & $22(48)$ & $18(30)$ & 0.07 \\
Small for gestational & $14(30)$ & $13(21)$ & 0.37 \\
age & & & \\
Steroid complete & $40(87)$ & $47(77)$ & 0.22 \\
Chorioamnionitis & $3(7)$ & $4(7)$ & 1 \\
White race & $39(85)$ & $47(77)$ & 0.46 \\
Multiple birth & $26(57)$ & $23(38)$ & 0.08 \\
Male & $27(59)$ & $24(39)$ & 0.05 \\
1-min Apgar score & $8(5-8)$ & $8(7-8)$ & 0.69 \\
5-min Apgar score & $9(8-9)$ & $9(8-9)$ & 0.27 \\
Cesarean section & $35(76)$ & $51(84)$ & 0.34 \\
\hline
\end{tabular}

* $P$-value tests for equal baseline year and implementation phase percentage by Fisher exact test; or equal means by Student's $t$ test; or equal distributions by Wilcoxon rank-sum test

${ }^{\mathrm{a}}$ Clinical definition applied. 3 out of 5 criteria must be met: maternal fever $>100.4 \mathrm{~F}$ twice or $>101 \mathrm{~F}$ once, maternal tachycardia, fetal tachycardia, fundal tenderness, foul-smelling vaginal discharge

reduction in CLD $(P=0.09)$ or in the combined outcome of CLD/death $(P=0.18)$ in infants $<1000 \mathrm{~g}$ birth weight; however, the subgroup was too small to show a significant subgroup difference. There were no significant differences in incidence rates of pneumothorax or pulmonary interstitial emphysema, hypotension treated with pressors, spontaneous perforations, nosocomial sepsis, and number of days in the hospital. The incidence of severe IVH was significantly lower (from 13 to $0 \% P=0.005$ ). Additionally, the need for surgical closure of a PDA was significantly decreased from 35 to $3 \%(P<0.0001)$. Although not statistically significant, there were decreases in severe ROP and NEC. The summary of NICU outcome measures is provided in Table 3 and Fig. 2.

As infants in the implementation phase were on average $106 \mathrm{~g}$ heavier, 1 week older and male gender was more prevalent—gender, birth weight, and GA were examined as potential confounders in multivariate logistic regression analysis to determine whether those covariates might account for the improved outcome in the implementation phase. Among the potential confounders, only birth weight and GA met the criteria of association with both outcome $(P<0.0001)$ and study phase $(P=0.06)$. Adjusting the logistic regression for any or all covariates had only a
Table 2 Respiratory management during baseline year and implementation phase

\begin{tabular}{|c|c|c|c|}
\hline \multirow[t]{2}{*}{ Outcome } & \multicolumn{2}{|c|}{$\begin{array}{l}N(\%) \text { or median } \\
\text { (minimum-maximum) }\end{array}$} & \multirow[t]{2}{*}{$P$-value* } \\
\hline & $\begin{array}{l}\text { Baseline } \\
\text { year }\end{array}$ & $\begin{array}{l}\text { Implementation } \\
\text { phase }\end{array}$ & \\
\hline All infants & $46(100)$ & $61(100)$ & - \\
\hline $\begin{array}{l}\text { CPAP therapy in } \\
\text { delivery room }\end{array}$ & $16(35)$ & $26(43)$ & 0.43 \\
\hline $\begin{array}{l}\text { NIPPV therapy in } \\
\text { delivery } \text { room }^{\mathrm{a}}\end{array}$ & $0(0)$ & $29(48)$ & $<0.0001$ \\
\hline $\begin{array}{l}\text { Intubated in delivery } \\
\text { room }\end{array}$ & $26(57)$ & $5(8)$ & $<0.0001$ \\
\hline Intubated any time & $36(78)$ & 30 (49) & 0.003 \\
\hline SIMV, any time & $35(76)$ & $31(51)$ & 0.009 \\
\hline HFOV, any time & $28(61)$ & $12(20)$ & $<0.0001$ \\
\hline NIPPV, any time & $25(54)$ & $40(66)$ & 0.32 \\
\hline CPAP, any time & $37(80)$ & 48 (79) & 1 \\
\hline HFNC, any time & $33(72)$ & $18(30)$ & $<0.0001$ \\
\hline LFNC, any time & $24(52)$ & $8(13)$ & $<0.0001$ \\
\hline Days on SIMV & $3(0-41)$ & $0.5(0-33)$ & 0.001 \\
\hline Days on HFOV & $1(0-40)$ & $0(0-23)$ & $<0.0001$ \\
\hline Days on CPAP & $4.5(0-31)$ & $5(0-38)$ & 0.28 \\
\hline Days on NIPPV & $1(0-29)$ & $1(0-31)$ & 0.58 \\
\hline Days on HFNC & $6.5(0-52)$ & $0(0-49)$ & $<0.0001$ \\
\hline Days on LFNC & $2.5(0-37)$ & $0(0-26)$ & $<0.0001$ \\
\hline $\begin{array}{l}\text { Surfactant } \\
\text { administration }\end{array}$ & $36(78)$ & $26(43)$ & 0.0003 \\
\hline $\begin{array}{l}\text { Caffeine started on } \\
\text { admission }\end{array}$ & $3(7)$ & $52(87)$ & $<0.0001$ \\
\hline Steroids for CLD & $10(22)$ & $5(8)$ & 0.054 \\
\hline $\begin{array}{l}\text { Infants with birth } \\
\text { weight }<1000 \mathrm{~g}\end{array}$ & $22(100)$ & $18(100)$ & - \\
\hline Intubated any time & $21(95)$ & $14(78)$ & 0.16 \\
\hline
\end{tabular}

* $P$-value tests for equal baseline year and implementation phase percentage by Fisher exact test; or equal distributions by Wilcoxon rank-sum test

${ }^{a}$ Excludes patients trialed on CPAP/NIPPV in DR, but failed

negligible effect on the magnitude or significance of the estimated odds ratio for CLD or death $(0.25)$ or its $95 \%$ CI (0.10-0.60). No evidence of effect modification was seen for any of the covariates $(P=0.24$ or greater).

\section{Missing data}

There were three unknown outcomes, two in the baseline year and one during the implementation phase. A sensitivity analysis assuming either positive or adverse outcome for all missing cases demonstrated that the results remained strong and significant. 
Table 3 NICU outcome measures during baseline year and implementation phase

\begin{tabular}{|c|c|c|c|}
\hline \multirow[t]{2}{*}{ Outcome } & \multicolumn{2}{|c|}{$N(\%)$ or mean $\pm \mathrm{SD}$} & \multirow[t]{2}{*}{$P$-value* } \\
\hline & $\begin{array}{l}\text { Baseline } \\
\text { year }\end{array}$ & $\begin{array}{l}\text { Implementation } \\
\text { phase }\end{array}$ & \\
\hline All infants & $46(100)$ & $61(100)$ & \\
\hline CLD or death & $22(50)$ & $12(20)$ & 0.002 \\
\hline CLD & $19(43)$ & $7(12)$ & 0.0006 \\
\hline Death & $5(11)$ & $5(8)$ & 0.74 \\
\hline $\mathrm{O}_{2}$ home & $3(7)$ & $0(0)$ & 0.07 \\
\hline PTX or PIE & $3(7)$ & $8(13)$ & 0.34 \\
\hline $\begin{array}{l}\text { Medical therapy for } \\
\text { PDA }\end{array}$ & $13(28)$ & $9(15)$ & 0.10 \\
\hline $\begin{array}{l}\text { Surgical therapy for } \\
\text { PDA }\end{array}$ & $16(35)$ & $2(3)$ & $<0.0001$ \\
\hline $\begin{array}{l}\text { Hypotension treated } \\
\text { with pressors }\end{array}$ & $11(24)$ & $8(13)$ & 0.20 \\
\hline $\begin{array}{l}\text { IVH Grade 3-4 } \\
\text { (severe) }\end{array}$ & $6(13)$ & $0(0)$ & 0.005 \\
\hline $\begin{array}{l}\text { ROP Stage 3-4 } \\
\text { (severe) }\end{array}$ & $4(10)$ & $1(2)$ & 0.16 \\
\hline NEC & $5(11)$ & $2(3)$ & 0.14 \\
\hline $\begin{array}{l}\text { Spontaneous } \\
\text { perforations }\end{array}$ & $2(4)$ & $1(2)$ & 0.58 \\
\hline Nosocomial sepsis & 8 (17) & $4(7)$ & 0.12 \\
\hline Hospital stay, d & $69.6 \pm 35.7$ & $60.6 \pm 32.9$ & 0.18 \\
\hline $\begin{array}{l}\text { Infants with birth } \\
\text { weight }<1000 \mathrm{~g}\end{array}$ & $22(100)$ & $18(100)$ & \\
\hline CLD or death & $16(76)$ & $9(53)$ & 0.18 \\
\hline CLD & $14(67)$ & $5(36)$ & 0.09 \\
\hline Death & $4(18)$ & $4(22)$ & 1 \\
\hline Infants with CLD & $19(100)$ & $7(100)$ & \\
\hline Moderate CLD ${ }^{\mathrm{a}}$ & $11(58)$ & $6(86)$ & 0.36 \\
\hline Severe $C^{2} D^{b}$ & $8(42)$ & $1(14)$ & \\
\hline
\end{tabular}

Effective FIO2 conversion for infants on nasal cannula adapted from Benaron and Benitz conversion [20]. Note: all infants diagnosed with CLD were $<32$ weeks gestational age at birth

$* P$-value tests for equal baseline year and implementation phase percentage by Fisher exact test; or equal means by Student's $t$ test

${ }^{a}$ Defined as need for supplemental oxygen for at least 28 days and need for supplemental oxygen with effective $\mathrm{FIO} 2<0.3$ at 36 weeks postmenstrual age [19]

${ }^{b}$ Defined as need for supplemental oxygen for at least 28 days and need for supplemental oxygen or positive pressure with effective $\mathrm{FIO} 2 \geq 0.3$ at 36 weeks postmenstrual age [19]

\section{Discussion}

Our data demonstrate that the introduction of a consistent respiratory bundle focusing on non-invasive ventilation was associated with a significant improvement in respiratory outcomes without an increase in negative outcomes among VLBW infants. The intervention is responsible for the reduction in CLD/death independent of the influence of gender, birth weight, and GA.

The number of days on SIMV, HFOV, HFNC, and LFNC was significantly lower when the Guideline was in use, although there was no significant increase in number of days on NIPPV or CPAP. The most likely explanation is that a more standardized approach to when and how to use both modes was implemented. It is also possible that avoidance of initial mechanical ventilation had protective effects on the developing lung that resulted in less need for non-invasive respiratory support.

The initial randomized-controlled trials and the most current Cochrane review concluded that NIPPV is superior to CPAP (less need to intubate, less extubation failures) [14-18]. Reported NIPPV effects on CLD/mortality are inconsistent. The most current trial comparing infants $<30$ weeks GA placed initially either on CPAP or NIPPV, found no difference in the rates of death/CLD and length of mechanical ventilation. However, the types of devices used in the study were not specified, and the NIPPV settings used differed significantly from our settings [25]. Ventilator-generated CPAP with RAM cannula prongs were already accepted by our NICU staff. Use of chinstraps was based on physiologic studies suggesting that minimizing air leak and monitoring mean airway pressure might be necessary for successful use of this device [26]. We also focused on prolonged CPAP therapy and avoidance of "too early" weaning to HFNC as previously published data suggest that HFNC should not be used as replacement of CPAP [27]. Other suggested strategies to decrease the rates of CLD include targeting saturation range $88-92 \%$ (chosen by our NICU) and decreasing the rates of nosocomial infections [28]. Our nosocomial infection rates decreased during the implementation phase, but did not reach statistical significance. A nurse-driven QI initiative "Eradicating CLABSIs in the NICU" began in October 2014 and continues. The initiative concentrated on hand hygiene, central line insertion techniques, limiting exposures to central lines, and introduction of a custommade central line tubing kit. Previous attempts to use QI methods to reduce the occurrence of CLD have met with variable success. The Vermont-Oxford Network noted limited improvement in CLD rates in the analysis of infants $<1000 \mathrm{~g}$ birth weight (a decrease from 43.5 to $31.5 \%$ ), with no significant effect on death or CLD/death rates in response to an extensive interinstitutional QI initiative [29]. Similarly, a cluster-randomized, multimodal, multicenter, QI trial involving 17 centers- changed respiratory practices, but did not reduce CLD rates among infants $<1250 \mathrm{~g}$ [30]. Wlodaver et al.[31] reported decreased need for the resuscitation in DR as a result of implementing a standardized approach in a center with $\sim 200$ VLBW infants delivered per year, but no effect on 
Fig. 2 Respiratory management and NICU outcomes: statistically significant changes during implementation phase

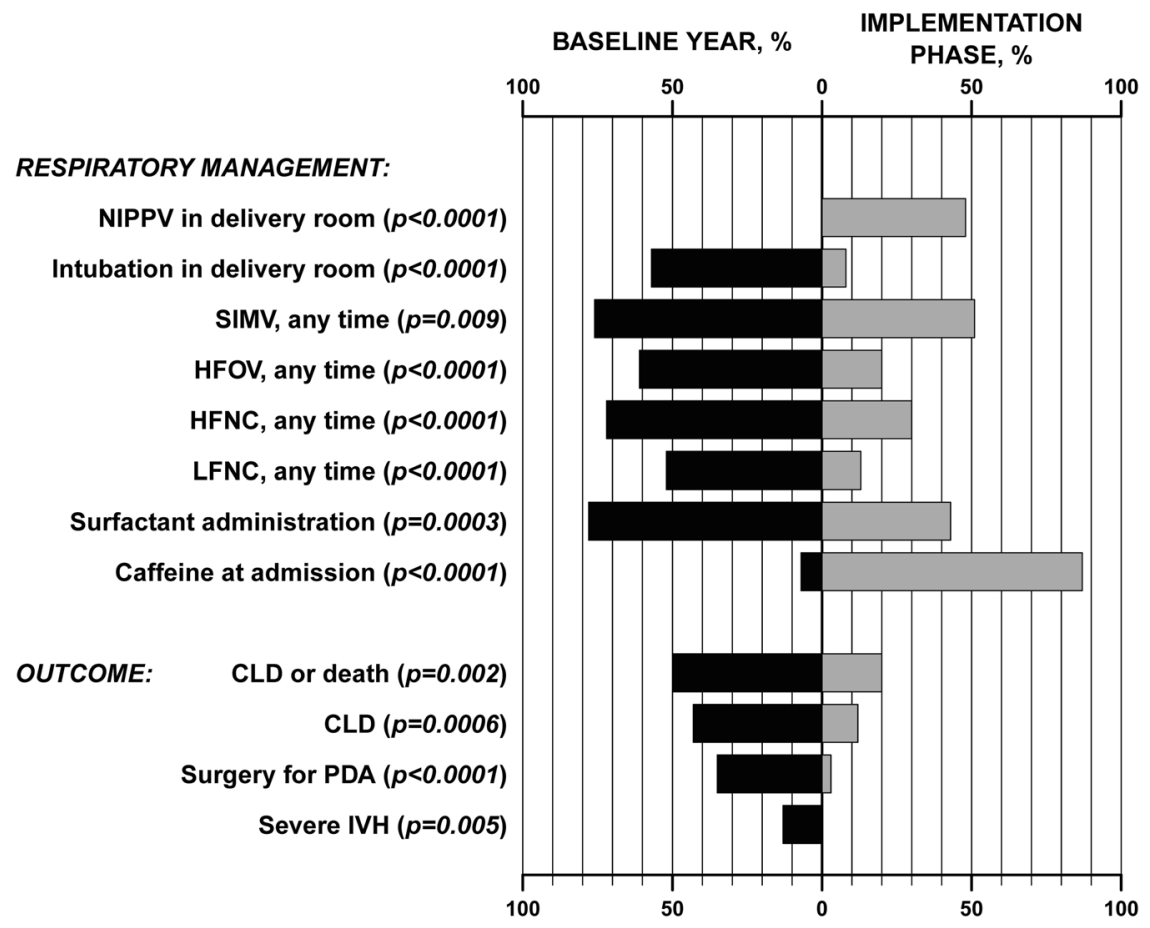

PEMENTATION
CLD rates. The NICUs involved in these studies were large and presumably involved multiple care providers.

Two previously published smaller QI initiatives demonstrated more encouraging results. Levesque et al. described a reduction in CLD from 17 to $8 \%$ among infants 26-32 and 6/7 weeks GA in a NICU with about 60 admissions $<33$ weeks GA per year. Their new respiratory practices were introduced at one time point and high compliance was indicated by significantly reduced mechanical ventilation. Similar to our small size NICU, the intervention resulted in improved outcomes despite using a different method of non-invasive ventilation [32]. Birenbaum et al. [33] reported a reduction in CLD from 46.5 to $20.5 \%$ among infants $<1500 \mathrm{~g}$ in a NICU, with $70 \mathrm{VLBW}$ infants admitted per year. Ours is the third report that we are aware of to present a decrease in CLD in a NICU with smaller numbers of patients, staff, and providers, whereas reports from larger NICUs have been less encouraging. This is the first report that includes infants as young as 24 weeks GA and focuses on NIPPV as a primary ventilation mode.

The most novel element of our project is nearly perfect compliance with the intervention as evidenced by significantly changed rates of multiple respiratory practices (Table 2). We attribute this highly effective implementation to several factors. Those include: staff awareness of our CLD rates and rates in VON network, interdisciplinary development of potentially better respiratory care practices, engaging and giving equal voice to all the participants from various disciplines, a period of intense education during which specialist-to-specialist teaching was used, and refresher activities after 12 and
24 months with real-time monitoring of deviations and prompt feedback. As a result, a new mental model of respiratory care was created, and there was a sense of pride and ownership among the team. Other human factors include twice-daily multidisciplinary rounds, a non-hierarchal approach to communication, and a small, cohesive team.

A limitation of our report is the relatively small number of infants, especially infants with birth weight $<1000 \mathrm{~g}$. The generalizability of these results within NICUs containing a larger number of caregivers, trainees, a different composition of the NICU, and DR teams is uncertain. Extremely high compliance with a QI project that involves major changes in practice might not be easily achievable.

\section{Conclusions}

The temporal association of improved outcomes with our intervention suggests that by implementing a respiratory bundle focusing on non-invasive ventilation and minimizing unwanted provider-dependent practice variation, major changes in practice can be achieved and lead to significantly improved respiratory outcomes.

Acknowledgements We wish to give special thanks to the very dedicated South Shore Hospital nurses, respiratory therapists, nurse practitioners, and neonatologists for embracing and mastering significant changes in our respiratory practices for the benefit of our patients. We would like to thank Martha Sola-Visner MD, Associate Professor of Pediatrics at Harvard Medical School and Dr. Munish Gupta from BIDMC for their intellectual support and assistance with preparing and reviewing this manuscript. 


\section{Compliance with ethical standards}

Conflict of interest The authors declare that they have no competing interests.

\section{References}

1 Pfister RH, Soll RF. Initial respiratory support of preterm infants. The role of CPAP, the INSURE method, and noninvasive ventilation. Clin Perinatol 2012;39:459-81.

2 Wright LL, Horbar JD, Gunkel H, Verter J, Younes N, Andrews $\mathrm{EB}$, et al. Evidence from multicenter networks on the current use and effectiveness of antenatal corticosteroids in low birth weight infants. Am J Obstet Gynecol 1995;173:263-9.

3 Roberts D, Dalziel S. Antenatal corticosteroids for accelerating fetal lung maturation for women at risk for preterm birth. Cochrane Database Syst Rev 2006;3:CD004454.

4 St John EB, Carlo WA. Respiratory distress syndrome in VLBW infants: changes in management and outcomes observed by the NICHD neonatal research network. Semin Perinatol 2003;27:288-92.

5 Avery ME, Tooley WH, Keller JB, Hurd SS, Bryan MH, Cotton $\mathrm{RB}$, et al. Is chronic lung disease in low birth weight infants preventable? A survey of eight centers. Pediatrics 1987;79:26-30.

6 Van Marter LJ, Allred EN, Pagano M, Sanocka U, Parad R, Moore $\mathrm{M}$, et al. Do clinical markers of barotrauma and oxygen toxicity explain interhospital variation in rates of chronic lung disease? Pediatrics 2000;105:1194-201.

7 Finer NN, Carlo WA, Walsh M, Higgins RD. Early CPAP versus surfactant in extremely preterm infants. SUPPORT Study Group of the Eunice Kennedy Shriver NICHD Neonatal Research Network. N Engl J Med 2010;362:1970-9.

8 Dunn MS, Kaempf J, de Klerk A, de Kerk R, Reilly M, Howard D, et al. Randomized trial comparing 3 approaches to the initial respiratory management of preterm neonates. Pediatrics 2011;128: e1069-76.

9 Fisher HS, Buhrer C. Avoiding endotracheal ventilation to prevent bronchopulmonary dysplasia: a meta-analysis. Pediatrics 2013;132:e1351-60.

10 Schmolzer GM, Kumar M, Pichler G, Aziz K, O'Reilly M, Cheung $\mathrm{P}$. Non-invasive versus invasive respiratory support in preterm infants at birth: systemic review and meta-analysis. BMJ 2013;347:f5980.

11 Respiratory support in preterm infants at birth. Committee on Fetus and Newborn. Pediatrics 2014;133:171-4.

12 Bahadue FL, Soll R. Early versus delayed selective surfactant treatment for neonatal respiratory distress syndrome. Cochrane Database Syst Rev 2012;11:CD001456.

13 Bhandari V. Nasal intermittent positive pressure ventilation in the newborn: review of literature and evidence-based guidelines. J Perinatol 2010;20:505-12.

14 Lemyre B, Davis PG, De Paoli AG. Nasal intermittent positive pressure ventilation (NIPPV) versus nasal continuous positive airway pressure (NCPAP) for apnea of prematurity. Cochrane Database Syst Rev 2002;10:CD002272.

15 Bhandari V, Gavino RG, Nedrelow JH, Pallela P, Salvador A, Ehrenkranz RA, et al. A randomized controlled trial of synchronized nasal intermittent positive pressure ventilation in RDS. J Perinatol 2007;27:697-703

16 Friedlich P, Lecart C, Posen R, Ramicone MS, Chan L, Ramanathan $\mathrm{R}$, et al. A randomized trial of nasopharyngeal- synchronized intermittent mandatory ventilation versus nasopharyngeal continuous positive airway pressure in very low birth weight infants after extubation. J Perinatol 1999;19:413-8.

17 Barrington KJ, Bull D, Finner NN. Randomized trial of nasal synchronized intermittent mandatory ventilation compared with continuous positive airway pressure after extubation of very low birth weight infants. Pediatrics 2001;107:638-41.

18 Khalaf MN, Brodsky N, Hurley J, Bhandari V. A prospective randomized, controlled trial comparing synchronized nasal intermittent positive pressure ventilation versus nasal continuous positive airway pressure as modes of extubation. Pediatrics 2001;108:13-17.

19 Jobe AH, Bancalari E. Bronchopulmonary dysplasia. Am J Respir Crit Care Med 2001;163:1723-9.

20 Benaron DA, Benitz WE. Maximizing the stability of oxygen delivered via nasal cannula. Arch Pediatr Adolesc Med. 1994;148:294-300.

21 Burstein J, Papile L, Berstein R. Intraventricular hemorrhage and hydrocephalus in the premature newborn: a prospective study with CT. Am J Radiol 1979;132:631-5.

22 Committee for the Classification of Retinopathy of Prematurity. An International Classification of Retinopathy of Prematurity. Arch Ophthalmol 1984;102:1130-4.

23 Walsh MC, Kliegman RM. Necrotizing enterocolitis: treatment based on staging criteria. Pediatr Clin North Am. 1986;33:179-201.

24 Provost LP, Murray S. The healthcare data guide: learning from data for improvement. San Francisco: Jossey-Bass Publishers; 2011. p. 107-36.

25 Kirpalani H, Millar D, Lemyre B, Yoder BA, Chiu A, Roberts RS. A trial comparing noninvasive ventilation strategies in preterm infants. N Engl J Med 2013;369:611-20.

26 Gerdes JS, Sivieri EM, Abbasi S. Factors influencing delivered mean airway pressure during nasal CPAP with the RAM cannula. Pediatr Pulmonol 2016;51:60-9.

27 Kubicka ZJ, Limauro J, Darnall RA. Heated, humidified high-flow nasal cannula therapy: yet another way to deliver continues positive airway pressure? Pediatrics 2008;121:82-8.

28 Nelin LD, Bhandari V. How to decrease bronchopulmonary dysplasia in your neonatal intensive care unit today and "tomorrow". F1000Res. 2017;6:539. https://doi.org/10.12688/f1000research. 10832.1.

29 Horbar JD, Rogowski J, Plsek PE, Delmore P, Edwards WH, Hocker J, et al. Collaborative quality improvement for neonatal intensive care. Pediatrics 2001;107:14-22.

30 Walsh M, Laptook A, Kazzi SN, Engle WA, Yao Q, Rasmussen $\mathrm{M}$, et al. A cluster-randomized trial of benchmarking and multimodal quality improvement to improve rates of survival free of bronchoplulmonary dysplasia for infants with birth weights of less than 1250grams. Pediatrics 2007;119:876-90.

31 Wlodaver A, Blunt M, Satnes K, Escobedo M, Hallford G, Szyld E. A retrospective comparison of VLBW outcomes before and after implementing new delivery room guidelines at a regional tertiary care center. J Perinatol 2016;36:182-5.

32 Levesque BM, Kalish LA, LaPierre J, Welch M, Porter V. Impact of implementing 5 potentially better respiratory practices on neonatal outcomes and costs. Pediatrics 2011;128:e218-26.

33 Birenbaum HJ, Dentry A, Cirelli J, Helou S, Pane MA, Starr K, et al. Reduction in the incidence of chronic lung disease in very low birth weight infants: results of quality improvement process in a tertiary level neonatal intensive care unit. Pediatrics 2009;123:44-50. 